\title{
Determination of eye Irritation Potential of Low-irritant Products: Comparison of in vitro Results with the in vivo Draize Rabbit Test
}

\author{
Andréa Martins da Nóbrega ${ }^{1}$, Eloisa Nunes Alves ${ }^{1}$, Rosaura de Farias Presgrave ${ }^{1}$, Rodrigo \\ Netto Costa ${ }^{2}$ and Isabella Fernandes Delgado ${ }^{2^{*}}$ \\ ${ }^{1}$ Departamento de Farmacologia e Toxicologia ${ }^{2}$ Deparatmento de Imunologia; Instituto Nacional de Controle de \\ Qualidade em Saúde; Fundação Oswaldo Cruz; Rio de Janeiro - RJ - Brasil
}

\begin{abstract}
In an attempt to build the evaluation strategies to assess the human eye irritation, a reassessment of some in vitro tests is necessary, particularly concerning the non-irritants, mild and moderate irritants. Thus, the correlations between results obtained from the Draize test with the in vitro methods HET-CAM (Hens Egg Test-Chorion Allantonic Membrane) and RBC haemolysis assay to assess the ocular irritancy potential of 20 eye drops were examined. Parameters such as accuracy (\%) and specificity (\%) were determined. All results were correlated with $R B C$ correctly with the results obtained in the Draize test. The HET-CAM presented four false-positive results, showing a tendency of data overestimation. Despite the high specificity provided mainly by the RBC, it would be necessary to test a wider range of products representing all the scales of irritation to confirm its ability to be used as a first alternative to test products that could be presumptive non-irritants.
\end{abstract}

Key words: Alternative methods, eye irritation, Draize Test, low-irritant, HET-CAM, RBC

\section{INTRODUCTION}

As a result of a number of injuries and deaths from the consumer products in the 1930s, the United States Congress approved the Federal Food, Drug and Cosmetic Act (1938), which obligated premarket safety testing for a variety of products. Animal-based toxicological test methods were developed at that time in response to a recognized need by the industry and government regulatory agencies for supplying reliable products to ensure the consumer safety (Wax 1995).

One component in the risk assessment of the cosmetics - and other products that may come into contact with the human ocular surface - is the determination of its potential to induce eye irritation. The Draize eye irritation test (Draize et al. 1944) has been used for about 60 years in attempt to predict human eye injury and it is based on topical instillation of the potential irritant and scoring of ocular adverse effects by examination of the rabbit eye (Wilhelmus 2001). This test has been a subject of controversy among the animal rights groups and even in the scientific community. It has been criticized on the basis of dose volume, methods of exposure, use of animals as models, number of animals, observation and scoring, including the laboratory procedure variability, interpretation of results and the over prediction of human response (Princen 2006). However, the Draize eye irritation test continues to be the primary method accepted by the regulatory agencies worldwide (Vinardell and Mitjans 2008; Scott et al. 2010).

*Author for correspondence: isabella.delgado@incqs.fiocruz.br 
Humane and scientific concerns regarding the use of animals in toxicology have prompted development of many in vitro methods as potential alternatives for animal tests. Despite some progress in the areas of reduction and refinement, no single test has emerged as being acceptable as a complete replacement for the conventional Draize test, so that development of a battery of nonanimal eye irritation alternative tests is actively being proposed (McNamme et al. 2009; Barile 2010).

On the development of in vitro eye irritation tests, a variety of methods such as cell-based cytotoxicity, reconstituted tissue models, chorioallantoic membrane (CAM) methods, isolated organ assays and other systems have been developed since the 1980s (North-Rooth et al. 1985; Luepke and Kemper 1986; Pape et al. 1987; Roguet et al. 1992; Balls et al. 1995; Harbell et al. 1997; Spielmann et al. 1997; Jones et al. 1999; Pape et al. 1999; Steiling et al. 1999; Cooper et al. 2001; Hutak et al. 2003; Eskes et al. 2005; Doucet et al. 2006; Vinardell and Mitjans 2006; Alves et al. 2008; Cater and Harbell 2008; Schutte et al. 2009; Takahashi et al. 2009). On the other hand, the relevance of some currently used in vitro tests for a reliable prediction of human eye irritation, particularly concerning mild and moderate irritants, is still uncertain. Recently, two alternative methods, i.e., the Bovine Corneal Opacity and Permeability (BCOP) and the Isolated Chicken Eye (ICE), have been scientifically validated (OECD 2009). However, those assays are solely employed to corrosive and severe ocular irritant ingredients, being not applicable to a great number of ingredients with low-irritant potential or products that produce human eye distress in the absence of macroscopic adverse clinical evidence. The present challenge is to develop a non-animal test method - or an assessment strategy - suitable to evaluate mild and moderate irritant materials (Debbasch et al. 2005; McNamme et al. 2009; Barile 2010).

In attempt to build up such an assessment strategy to evaluate the human eye irritation, a reevaluation of some currently used in vitro tests is needed, particularly concerning the non-irritants, mild and moderate irritants. Therefore, in the present study, we investigated the irritation potential of products previously tested in vivo: (i) in the Red Blood Cell (RBC) haemolysis assay, and (ii) in the Hen's Egg Test-Chorioallantoic membrane (HET-CAM). According to a recently proposed in vitro testing strategy approach for eye irritation called "Botton-Up Approach" (Scott et al. 2010), these two assays are part of a group of in vitro tests that have the greatest potential to distinguish the non-classified substances from irritants. Thus, the aim of the present study was to investigate the relevance of HET-CAM and RBC test methods in the assessment of irritant potential of low-irritant products and to correlate their results with those of in vivo Draize eye irritation test.

\section{MATERIAL AND METHODS}

\section{Test substances}

The products used in the present study comprised 20 eye drops acquired from the commercial establishments in Rio de Janeiro, Brazil. A description of the product formulations used in this study can be found in Table 1 .

\section{The in vivo test}

The Draize test was previously performed in the laboratory routinely and the results described belonged to the database bank. Thus, the in vivo test was performed as follows. Five male or female New Zeland albino rabbits, weighing $2-3 \mathrm{~kg}$, were used in the in vivo test. The animals were maintained in individual cages, with water and food ad libitum, at $20+2^{\circ} \mathrm{C}$ and humidity of $70 \%$. The protocol of the ocular irritation test was approved by the Animal Use Ethics Commission (CEUA/FIOCRUZ). One hundred microlitres of each product were instilled into one of the eyes, following by massaging for 30 seconds, while the other eye was used as control. The reading were performed at $24,48,72 \mathrm{~h}$ and seven days after the application, and the corneal, iris and conjunctival alterations were graded according to the Draize scale (Draize et al. 1944). To classify the eye irritation potentials of the products, the Kay and Calandra methodology was used (Kay and Calandra 1962), which took into account the persistence and severity of the irritation response. After the last reading, the animals were euthanasiated by intravenously injection of $100 \mathrm{mg}$ thiopental/Kg. 
Table 1 - List of tested eye drops.

\begin{tabular}{|c|c|}
\hline Eye Drop & Formulation \\
\hline $\mathrm{CO} 01$ & $\begin{array}{l}\text { Zinc salt }(1.0 \mathrm{mg}) \text {, naphazoline hydrochloride }(0.5 \mathrm{mg}) \text {, vehicle berberine sulphate, hydrated } \\
\text { chlorobutanol, benzalkonium chloride, sodium citrate, glycerin, hydroxypropyl cellulose, purified water. }\end{array}$ \\
\hline $\mathrm{CO} 02$ & $\begin{array}{l}\text { Hydrochloride methylthioninium (0.015), hydrochloride tetrahydrozoline }(0.5 \mathrm{mg}) \text {. Excipients: } \\
\text { hydroxypropyl methylcellulose, monobasic sodium phosphate, disodium phosphate, sodium chloride, } \\
\text { benzalkonium chloride, disodium edetate, purified water. }\end{array}$ \\
\hline $\mathrm{CO} 03$ & $\begin{array}{l}\text { Naphazoline hydrochloride }(0.15 \mathrm{mg}) \text {, zinc sulfate }(0.3 \mathrm{mg}) \text {, vehicle: boric acid, sodium borate, } \\
\text { benzalkonium chloride, disodium edetate, water for injection. }\end{array}$ \\
\hline $\mathrm{CO} 04$ & $\begin{array}{l}\text { Methylthioninium hydrochloride }(0.15 \mathrm{mg}) \text {, tetrahydrozoline hydrochloride }(0.5 \mathrm{mg}) \text {, vehicle: boric } \\
\text { acid, borax, sodium chloride, disodium edetate, benzalkonium chloride as a preservative and distilled } \\
\text { water }(1 \mathrm{ml}) \text {. }\end{array}$ \\
\hline $\mathrm{CO} 05$ & $\begin{array}{l}\text { llorobutanol }(2.132 \mathrm{mg}) \text {, boric acid }(21.911 \mathrm{mg}) \text {, sodium chloride }(4.361 \mathrm{mg}) \text {, vehicle: sterile } \\
\text { rrified water. }\end{array}$ \\
\hline $\mathrm{CO} 06$ & $\begin{array}{l}\text { Naphazoline hydrochloride }(0.12 \mathrm{mg}) \text {, vehicle consisting of dextran } 70 \text {, hypromellose, potassium } \\
\text { chloride, sodium hydroxide and / or hydrochloric acid, with disodium edetate and benzalkonium } \\
\text { chloride as preservative and purified water }(1 \mathrm{ml}) \text {. }\end{array}$ \\
\hline $\mathrm{CO} 07$ & $\begin{array}{l}\text { Dlyvinyl alcohol ( } 14 \mathrm{mg}) \text {, excipients: sodium chloride, benzalkonium chloride, edetate disodium, } \\
\text { basic sodium phosphate hepta hydrate, sodium phosphate monobasic monohydrate and purified } \\
\text { ater. }\end{array}$ \\
\hline $\mathrm{CO} 08$ & $\begin{array}{l}\text { londroitin sulfate }(0.03 \mathrm{mg}) \text {, vehicle: Sodium hyaluronate, aprotinin, potassium sorbate, sodium } \\
\text { loride, disodium edetate and purified water. }\end{array}$ \\
\hline $\mathrm{CO} 09$ & $\begin{array}{l}\text { Dextran } 70(0.001 \mathrm{~g}) \text { and hypromellose }(0.003 \mathrm{~g}) \text {, vehicle: sodium borate, sodium chloride, potassium } \\
\text { chloride (as a preservative) and purified water }(1 \mathrm{ml}) \text {. }\end{array}$ \\
\hline $\mathrm{CO} 10$ & $\begin{array}{l}\text { Naphazoline hydrochloride }(0.25 \mathrm{mg}) \text {, Pheniramine maleate }(3 \mathrm{mg}) \text {, vehicle: boric acid, borax } \\
\text { disodium edetate, benzalkonium chloride as a preservative and purified water }(1 \mathrm{ml}) \text {. }\end{array}$ \\
\hline $\mathrm{CO} 11$ & $\begin{array}{l}\text { Pranoprofen ( } 1 \mathrm{mg}) \text {, vehicle: boric acid, sodium borate, polysorbate } 80 \text {, disodium edetate, } \\
\text { benzalkonium chloride and purified water. }\end{array}$ \\
\hline $\mathrm{CO} 12$ & $\begin{array}{l}\text { dium cromoglycate ( } 20 \text { and } 40 \mathrm{mg} \text { ), vehicle: sodium edetate, benzalkonium chloride (as a } \\
\text { eservative) and purified water }(1 \mathrm{ml}) \text {. }\end{array}$ \\
\hline CO13 & $\begin{array}{l}\text { trahydrozoline hydrochloride }(0.5 \mathrm{mg}) \text {, zinc sulfate }(1 \mathrm{ml}) \text { vehicle: methylene blue, boric acid, } \\
\text { dium citrate, polysorbate } 80 \text {, benzalkonium chloride and purified water. }\end{array}$ \\
\hline $\mathrm{CO} 14$ & $\begin{array}{l}\text { Dexamethasone }(1 \mathrm{mg}) \text {, chloramphenicol }(5 \mathrm{mg}) \text {, vehicle: boric acid, borax, chlorhexidine gluconate, } \\
\text { edetate disodium, Cremophor RH40, plasdone, sodium bisulfite, creatinine and purified water. }\end{array}$ \\
\hline $\mathrm{CO} 15$ & $\begin{array}{l}\text { Hypromellose }(5 \mathrm{mg}) \text {, vehicle: sodium phosphate dibasic, sodium phosphate monobasic, sodium } \\
\text { chloride, potassium chloride, sodium citrate, edetate disodium, methylparaben, propylparaben and } \\
\text { purified water. }\end{array}$ \\
\hline CO16 & $\begin{array}{l}\text { Benzalkonium chloride }(0.1 \mathrm{mg}) \text {, boric acid }(17 \mathrm{mg}) \text { vehicle: } 0.1 \mathrm{ml} \text { hidrolact chamomile, } 0.1 \mathrm{ml} \text { of } \\
\text { hidrolact hamamelis, sodium borate }(3 \mathrm{mg}) \text { and purified water. }\end{array}$ \\
\hline CO17 & $\begin{array}{l}\text { Phenylephrine hydrochloride (100mg), vehicle: sodium citrate dihydrate, sodium metabisulfite, } \\
\text { disodium edetate, benzalkonium chloride and purified water. }\end{array}$ \\
\hline CO18 & $\begin{array}{l}\text { Cromolyn }(20 \mathrm{mg}) \text {, vehicle: disodium edetate, benzalkonium chloride (as a preservative) and purified } \\
\text { water. }\end{array}$ \\
\hline CO19 & ospaglumic acid sodium salt (49 mg), vehicle: benzalkonium chloride and purified water. \\
\hline $\mathrm{CO} 20$ & $\begin{array}{l}\text { Dexamethasone }(0.05 \mathrm{mg}) \text {, chloramphenicol }(5 \mathrm{mg}) \text {, tetrizolina hydrochloride }(0.25 \mathrm{mg}) \text {, Vehicle: } \\
\text { hypromellose, boric acid, borax, disodium edetate, thimerosal, polyvinylpyrrolidone and purified } \\
\text { water. }\end{array}$ \\
\hline
\end{tabular}

\section{RBC assay \\ Preparation of the erythrocyte suspension}

Defibrinated sheep blood was obtained from the Laboratory Animals Breeding Center (CECAL) at the Oswaldo Cruz Foundation, Rio de Janeiro, Brazil. Erythrocytes were separated by centrifugation at $1302 \mathrm{~g}$ for 15 minutes at room temperature, washed three times with phosphatebuffered saline solution (PBS, $\mathrm{pH} 7.4$ ), and resuspended at a concentration of $8 \times 10^{9}$ cells $/ \mathrm{ml}$ in PBS supplemented with $10 \mathrm{nmol} / 1$ glucose. This suspension was maintained at $4^{\circ} \mathrm{C}$ for up to four weeks. The cells were returned to room temperature prior to the use. 


\section{The assay procedure}

The assay was performed according to the method of Pape et al., (1987). Eight concentration of each product diluted in PBS were incubated with erythrocytes $\left(8 \times 10^{9}\right.$ cells $\left./ \mathrm{ml}\right)$ for ten minutes, with constant shaking at room temperature. The incubation was terminated by a high-speed $(7520 \mathrm{~g})$ centrifugation. The extent of haemolysis was determined spectrophotometrically (UV-160A UV/VIS dual-beam spectrophotometer; Shimadzu Corporation, Kyoto, Japan) at 540nm against a blank, which contained only the sample diluted in PBS. The hemoglobin denaturation was assessed by monitoring the absorbance at 575 and $540 \mathrm{~nm}$ (UV-160A; Shimadzu Corporation), against a blank containing only the sample diluted in PBS. The denaturation index was calculated as DI [(R1$\mathrm{Ri}) /(\mathrm{R} 1-\mathrm{R} 2)] \times 100$, where R1, R2 and Ri were the ratios between the absorbance readings of the hemoglobin released from the erythrocytes when in contact with: (i) distilled water; (ii) sodium lauryl sulphate at $1 \mathrm{mg} / \mathrm{ml}$ and (iii) the product under analysis, respectively.

The extent of haemolysis, expressed as a percentage, was calculated as the absorbance of an erythrocyte suspension incubated with each product, relative to that of a completely hemolysed control $(100 \%)$ at $540 \mathrm{~nm}$. The $\mathrm{H}_{50}$ was determined from the concentration-response curves. The irritation potential (IP), defined as the $\mathrm{H}_{50} / \mathrm{DI}$ ratio, was used for comparison with the data obtained in vivo.

\section{HET-CAM assay}

The HET-CAM assay was carried out in accordance with the official method (Journal Officiel de la Republique Française 1996). Tenday-old fertilized eggs from White Leghorn chicken were incubated on an automatic rotating device (Premium Ecológica, Minas Gerais, Brazil) at $38.0 \pm 0.5^{\circ} \mathrm{C}$ and $70 \%$ relative humidity. The eggs were obtained from the Immunobiological Technology Institute (Bio-Manguinhos) at the Oswaldo Cruz Foundation, Rio de Janeiro, Brazil. On day 10 of incubation, the egg shell was opened at the side of the air chamber and the inner egg membrane was carefully removed avoiding any damage to the fine blood vessels of CAM. Three hundred microliters undiluted test products were applied to the chorioallantoic membrane. Four eggs were used for each product. After 20 seconds of contact, the membrane was rinsed with $37^{\circ} \mathrm{C}$ isotonic $\mathrm{NaCl}$ solution. The time up to appearance of the reactions (hyperaemia, haemorrhage, and coagulation) was assessed and the overall irritation score (0 to 21) was calculated as the mean sum of individual scores of all the endpoints from three replicate assays.

\section{Statistical Analysis}

The results obtained in this study were analyzed by using the performance comparisons between the in vitro assays and the Draize eye irritation test, derived from the contingency tables. The following values were calculated: specificity (the ratio of in vivo non-irritants classified in vitro as non-irritants); accuracy (the ratio of product classes [irritants and non-irritants] correctly classified in vitro) and false positives. Sensitivity (the ratio of in vivo irritants classified in vitro as irritants) was not determined, since not a single positive result was obtained in the in vivo test, and therefore also there were no false negatives.

\section{RESULTS}

The in vitro and in vivo irritation potential of the products analyzed in this study are described in Table 2. All the eye drops tested in vivo $(\mathrm{N}=20)$ were classified as non-irritants. This same classification was obtained in the RBC assay. However, in the HET-CAM test, the products $\mathrm{CO} 03, \mathrm{CO} 05, \mathrm{CO} 07$ and $\mathrm{CO} 17$ were classified as slight irritants.

\section{Predictive abilities}

The predictive abilities of the RBC and HETCAM assays in relation to the Draize Test were evaluated. For such, a contingency table comparing both in vitro assays with the in vivo test was set up (Table 3). The comparison of the RBC assay with the Draize Test showed 100\% specificity and accuracy. When the HET-CAM assay was compared with the Draize Test, specificity and accuracy were $80 \%$. Four products showed false positive responses (CO03, CO05, CO07 and CO17), as demonstrated in Table 4. 
Table 2 - Comparison of classification between the in vitro assays and the in vivo Draize test.

\begin{tabular}{|c|c|c|c|c|c|c|}
\hline \multirow[t]{2}{*}{ Product } & \multicolumn{2}{|r|}{ in vivo } & \multicolumn{2}{|c|}{ HET-CAM } & \multicolumn{2}{|r|}{ RBC } \\
\hline & MAS & Classification & Score & Classification & $\mathrm{H}_{50} / \mathrm{DI}$ & Classification \\
\hline \multicolumn{7}{|l|}{ Eye drops } \\
\hline $\mathrm{CO} 01$ & 0 & No irritant & 0.88 & No irritant & $>100$ & No irritant \\
\hline $\mathrm{CO} 02$ & 0 & No irritant & 0.14 & No irritant & $>100$ & No irritant \\
\hline $\mathrm{CO} 03$ & 0 & No irritant & 1.20 & Slight & $>100$ & No irritant \\
\hline $\mathrm{CO} 04$ & 0 & No irritant & 0.25 & No irritant & $>100$ & No irritant \\
\hline $\mathrm{CO} 05$ & 0 & No irritant & 1.12 & Slight & $>100$ & No irritant \\
\hline $\mathrm{CO} 66$ & 0.4 & No irritant & 0.30 & No irritant & $>100$ & No irritant \\
\hline $\mathrm{CO} 07$ & 0 & No irritant & 2.45 & Slight & $>100$ & No irritant \\
\hline $\mathrm{CO} 08$ & 0 & No irritant & 0.25 & No irritant & $>100$ & No irritant \\
\hline CO09 & 0 & No irritant & 0.65 & No irritant & $>100$ & No irritant \\
\hline $\mathrm{CO} 10$ & 0 & No irritant & 0.35 & No irritant & $>100$ & No irritant \\
\hline $\mathrm{CO} 11$ & 0.4 & No irritant & 0.25 & No irritant & $>100$ & No irritant \\
\hline $\mathrm{CO} 12$ & 0 & No irritant & 0.25 & No irritant & $>100$ & No irritant \\
\hline CO13 & 0 & No irritant & 0.18 & No irritant & $>100$ & No irritant \\
\hline $\mathrm{CO} 14$ & 0 & No irritant & 0.30 & No irritant & $>100$ & No irritant \\
\hline CO15 & 0 & No irritant & 0.17 & No irritant & $>100$ & No irritant \\
\hline CO16 & 0 & No irritant & 0.23 & No irritant & $>100$ & No irritant \\
\hline $\mathrm{CO} 17$ & 0.8 & No irritant & 2.23 & Slight & $>100$ & No irritant \\
\hline CO18 & 0.4 & No irritant & 0.38 & No irritant & $>100$ & No irritant \\
\hline CO19 & 0 & No irritant & 0.27 & No irritant & $>100$ & No irritant \\
\hline $\mathrm{CO} 20$ & 0.4 & No irritant & 0.32 & No irritant & $>100$ & No irritant \\
\hline
\end{tabular}

MAS = maximum average score; $\mathrm{H}_{50} / \mathrm{DI}=$ Irritation potential.

Table 3 - Contigency table.

\begin{tabular}{lccc} 
& & \multicolumn{2}{c}{ In vivo classification } \\
\cline { 2 - 3 } In vitro classification & & Irritant & Non-irritant \\
RBC assay & Irritant & 0 & 0 \\
& Non-irritant & 0 & 20 \\
HET-CAM assay & Irritant & 0 & 4 \\
& Non-irritant & 0 & 16 \\
\hline
\end{tabular}

Table 4 - Predictability of the in vitro assays for the 20 tested products.

\begin{tabular}{lcc}
\hline Parameter & RBC $(\boldsymbol{\%})$ & HET-CAM (\%) \\
\cline { 2 - 3 } Sensitivity & ND & ND \\
Specificity & 100 & 80 \\
Accuracy & 100 & 80 \\
False negatives & ND & ND \\
False positives & 0 & 4 \\
\hline
\end{tabular}

ND: Not determined.

\section{DISCUSSION}

For validation, new toxicological test methods must demonstrate their reliability, which means repeatable and reproducible, and that they are relevant, which means the method is predictive and has a biological basis for the stated purpose (Salem and Katz 2003). For the assessment of eye irritation, the Draize test - despite its limitations continues to be the only test accepted by the international regulatory agencies and no in vitro test has successfully been validated to fully replace it for regulatory purposes (Barile 2010). 
Although the in vitro HET-CAM test has been described as a suitable alternative method for the assessment of eye irritation of water-soluble, especially surfactant-containing materials (Luepke and Kemper 1986; Steiling et al. 1999), some authors have reported a poor correlation of HETCAM results with those of in vivo Draize test (Doucet et al. 1999; Debbasch et al. 2005). Despite the fact that HET-CAM had been accepted by the European Union to identify the ocular corrosives and severe irritants in July 2004 (McNamme et al. 2009), after about two years, the Interagency Coordinating Committee on the Validation of Alternative Methods (ICCVAM) did not recommended the HET-CAM as a screening test for the detection of ocular corrosives and severe irritants by not considering in this test a sufficient performance or an adequate amount of robust data to substantiate its use for the regulatory hazard (ICCVAM 2006). Consequently, the HET-CAM was not recommended as a screening test for the specific detection of that kind of irritants, but was deemed useful for other objectives such as for example, to identify the non-irritants (Scott et al. 2010; Scheel et al. 2011). In this specific goal, the RBC - an assay that is based on scientific and industry experience - is accepted as being "suitable for purpose" although not officially accepted by the regulatory agencies (McNamme et al. 2009), is quite similar to the HET-CAM in the recent proposed eye irritation testing strategy called "Bottom-Up approach" to test the materials estimated to have a no to low eye irritancy potential (Scott et al. 2010), what would really be interested in the area of quality control of products, subject to the action of Sanitary Surveillance (e.g. cosmetics such as shampoos, conditioners, makeup, medicinal products for ophthalmic use).

The HET-CAM provides information on the effects that may occur in the conjunctiva following exposure to a test substance. In the case of RBC, the effects are more related to the corneal damage (McNamme et al. 2009). The extent of involvement of the different ocular structures in the irritation is usually a reflection of the severity of the response. All categories of irritants cause some degree of alteration in the conjunctiva. The corneal injury ranges according to the potential irritant: (i) Slight irritants tend to affect the superficial corneal epithelium, (ii) Moderate irritants affect beside epithelium, the superficial stroma, and (iii) Severe irritants affect deeper layers of the stroma. In other words, depending on the mechanism of injury caused by a test substance (membrane lysis, protein coagulation, saponification or action on macromolecules), its effect will be better correlated with a specific ocular structure and which in turn will be better related to some specific in vitro methods. The HET-CAM and RBC, both have in common the feature to assess the potential of a test substance to disrupt the cellular membranes (Scott et al. 2010). Thus, in order to identify the irritants over the entire potency range for all kind of chemical classes, it is generally accepted that a battery of alternative methods will be required, since no single assay will fully replace the Draize test (Barile 2010).

In the present study, 20 eye drops presumably nonirritants, having been confirmed as such in the Draize test were tested in the in vitro HET-CAM and RBC assays to correlate their results with those of Draize Test with the main purpose of getting a preliminary evaluation of their real applicability on the first step of the "Botton-Up Approach". In this strategy, if test results indicated that the product or material was non-irritant, no additional tests would be needed. Otherwise, if a test substance was classified with any degree of irritation, an additional appropriate validated and highly reliable in vitro test to identify the real classification of the substance would be needed in the next step of the proposed battery. However, to definitely implement this type of approach, it would be necessary that international regulatory authorities accept the scientific validity of assays capable of accurately identifying negative results, without enforcing the need for confirmatory animal results (Scott et al. 2010).

With the data found in the present evaluation, The RBC was better than the HET-CAM in terms of predictability, because all the 20 results obtained in the RBC assay were correctly correlated with the Draize Test (Table 2). These results were consistent with recently published studies that showed good applicability of RBC in the evaluation of ocular irritation induced by the surfactants (Mehling et al. 2007; Mitjans et al. 2008) and finished products (Alves et al. 2008). The HET-CAM assay gave both specificity and accuracy of $80 \%$, overestimating the in vivo results. The fact that HET-CAM method overestimated the results obtained in vivo had been described previously and was probably due to the conditions of exposure to the product which was 
applied directly into the chorio-allantoic membrane, taking into account the fragility of blood capillaries of the chorioallantoic membrane and the high, non- physiological osmolality of some test substances (Hagino et al. 1999; Debbasch et al. 2005).

Finally, it is noteworthy that the prospect of definitive replacing the Draize eye irritation test by an in vitro strategy requires a wide knowledge of the models involved, including a better understanding of the mechanisms of eye irritation, and, therefore, further studies in this area are still required. The key challenge for the regulatory agencies and industries that have an interest in this theme is to develop an evaluation strategy, which will be built on scientific knowledge.

\section{CONCLUSION}

The results suggested that both the RBC and the HET-CAM test were feasible and easy to perform, when compared to the Draize test, but the HETCAM tended to overestimate the results in vivo. The RBC assay showed to be more susceptible to evaluate the low-irritant products, as it correlated exactly with the in vivo test. However, it would be necessary to conduct a more comprehensive evaluation with a larger number of products representing various categories of irritation in an inter-laboratory study to confirm these results.

\section{ACKNOWLEDGMENTS}

Andréa Martins da Nóbrega has a fellowship of PIBIC (CNPq/Fiocruz). This study was supported by PDTSP-SUS/Fiocruz and MCT/CNPq 14/2008. Isabella Fernandes Delgado is recipient of fellowship from CNPq.

\section{REFERENCES}

Alves EN, Presgrave R de F, Presgrave OAF, Sabagh FP, de Freitas JCBR, Corrado AP. A reassessment of the in vitro RBC haemolysis assay with defibrinated sheep blood for the determination of the ocular irritation potential of cosmetic products: comparison with the in vivo Draize rabbit test. ATLA. 2008; 36: 275-284.

Balls M, Botham PA, Bruner LH, Spielmann H. The $\mathrm{EC} / \mathrm{HO}$ international validation study on alternatives to the Draize eye irritation test for classification and labeling of chemicals. Toxicol in Vitro. 1995; 9: 871929.

Barile FA. Validating and troubleshooting ocular in vitro toxicology tests. J Pharmacol Toxicol Methods. 2010; 61: 136-145.

Cater K, Harbell J. Comparison of in vitro eye irritation potential by bovine corneal opacity and permeability (BCOP) assay to erythema scores in human eye sting test of surfactant-based formulations. Cutan Ocul Toxicol. 2008; 27: 77-85.

Cooper KJ, Earl LK, Harbell J, Raabe H. Prediction of ocular irritancy of prototype shampoo formulations by the isolated rabbit eye (IRE) test and bovine corneal opacity and permeability (BCOP) assay. Toxicol in Vitro. 2001. 15 (2): 95-103.

Debbasch C, Ebenhahn C, Dami N, Pericoi M, Van den Berghe C, Cottin M, et al.. Eye irritation of lowirritant cosmetic formulations: correlation of in vitro results with clinical data and product composition. Food Chem Toxicol. 2005; 43: 155-165.

Doucet O, Lanvin M, Zastrow L. Comparison of three in vitro methods for the assessment of eye irritation potential of formulated products. In Vitro $\mathrm{Mol}$ Toxicol. 1999; 12: 63-76.

Doucet O, Lanvin M, Thillou C, Linossier C, Pupat C, Merlin B, et al. Reconstituted human corneal epithelium: a new alternative to the Draize eye test for the assessment of the eye irritation potential of chemicals and cosmetic products. Toxicol In Vitro. 20: 499-512.

Draize JH, Woodard G, Calvery OH. Methods for the study of irritation and toxicity of substances applied topically to the skin and mucous membranes. $J$ Pharmacol Exp Ther. 1944; 83: 377-390.

Eskes C, Bessou S, Bruner L, Curren R, Harbell J, Jones P, et al. Eye irritation. ATLA. 2005; 33 (1): 4781.

Hagino S, Kinoshita S, Tani N, Nakamura T, Ono N, Konishi $\mathrm{K}$, et al. Interlaboratory validation of in vitro eye irritation tests for cosmetic ingredients. (2) Chorionallantoic Membrane (CAM) test. Toxicol In vitro. 1999; 13: 99-113.

Harbell J, Koontz SW, Lewis RW, Lovell D, Acosta D. IRAG working group 4: cell cytotoxicity assays. Food Chem Toxicol. 1997; 35: 79-126.

Hutak MC, Kavanagh ME, Agarwal V, Afouna MI, Khan MA, Reddy IK. Use of SIRC rabbit corneal cell lines grown on polycarbonate-or polyester-based filters to assess the in vitro corneal transport/toxicity screening using pilocarpine with or without benzalkonium chloride. J Toxicol. 2003; 22: 101-114.

ICCVAM. Test method evaluation report: In vitro ocular toxicity test methods for identifying severe irritants and corrosives. NIH Publication No.: 064511, National Toxicology Program (NTP), NICEATM, NIEHS, NIH, U.S. Public Health 
Service, Department of Health and Human Services; 2006.

Jones PA, Bracher M, Marenus K, Kojima $\mathrm{H}$. Performance of the neutral red uptake assay in the COLIPA international validation study on alternatives to the rabbit eye test. Toxicol In Vitro. 1999; 13 (2): 325-333.

Journal Officiel de la Republique Française. Aretê du 27 decémbre 1996 relatif aux méthodes d'analyse nécessaires au controle de la composition dês produits cosmétiques. Annexxe IV: méthode officialle d'évaluation du potencial irritant par application sur la membrane chorioallantoidienne del'oeuf de poule. 1996. 19137-19138.

Kay JH, Calandra JC. Interpretation of eye irritation tests. J Soc Cosmet Chem. 1962; 13: 281-289.

Luepke NP, Kemper FH. The HET-CAM test: An alternative o the Draize eye test. Food Chem Toxicol. 1986; 24 (6/7): 495-496.

McNamme P, Hibatallah J, Costabel-Farkas M, Goebel C, Araki D, Dufour E, et al. A tiered approach to the use of alternatives to animal testing for the safety assessment of cosmetics: Eye irritation. Regul Toxicol Pharmacol. 2009; 54: 197-209.

Mehling A, Kleber M, Hensen H.Comparative studies on the ocular and dermal irritation potential of surfactants. Food Chem Toxicol. 2007; 45 (5): 747 758.

Mitjans M, Infante M R, Vianrdell M P. Human hemoglobin denaturation as an alternative to the Draize test for predicting eye irritancy of surfactants. Regul Toxicol Pharmacol. 2008; 52 (2): 89-93.

North-Rooth H, Yackovich F, Demetrulias J, Gagula M, Heinze JE. Prediction of the eye irritation potential of shampoos using the in vitro SIRC cell toxicity test. Food Chem Toxicol. 1985; 23 (2): 271-273.

OECD. Guideline for the testing of chemicals No. 437: Bovine Corneal Opacity and Permeability test Method for Identifying Ocular Corrosives and Severe Irritants. Paris. 2009. 18.

Pape WJW, Pfannenbecker U, Hoppe U. Validation of the red blood cell test system as in vitro assay for the rapid screening of irritation potential of surfactants. Mol Toxicol. 1987; 1: 525-536.

Pape WJW, Pfannenbecker U, Argembeaux H, Bracher M, Esdaile DJ, Hagino S, et al. COLIPA validation project on in vitro eye irritation tests for cosmetic ingredients and finished products (phase I): the red blood cell test for the estimation of acute eye irritation potentials. Present status. Toxicol In Vitro. 1999; 13 (2): 343-354.

Princen MK. The Draize Eye Test and in vitro alternatives; a left-handed marriage? Toxicol in Vitro. 2006; 20: 78-81.
Roguet R, Dossou KG, Rougier A. Prediction of eye irritation potential of surfactants using the SIRCNRU cytotoxicity test. Third SPTC Meeting. ATLA. 1992; 20: 451-456.

Salem H, Katz SA. Alternative toxicological methods. Boca Raton: CRC Press; 2003.

Scheel J, Kleber M, Kreutz J, Lehringer E, Mehling A, Reisinger K, et al. Eye irritation potential: Usefulness of the HET-CAM under the Globally Harmonized System of Classification and Labeling of Chemicals (GHS). Regul Toxicol Pharmacol. 2011; 59: 471-492.

Schutte K, Prinsen MK, McNamee PM, Roggeband R. The isolated chicken eye test as a suitable in vitro method for determining the eye irritation potential of household cleaning products. Regul Toxicol Pharmacol. 2009; 54 (3): 272-281.

Scott L, Eskes C, Hoffmann S, Adriaens E, Alepée N, Bufo $\mathrm{M}$, et al. A proposed eye irritation testing strategy to reduce and replace in vivo studies using Bottom-Up and Top-Down approaches. Toxicol in Vitro. 2010; 24: 1-9.

Spielmann H, Liebsch M, Moldenhauer F, Holzhütter HG, Bagley DM, Lipman JM, et al. IRAG working group 2: CAM-based assays. Food Chem Toxicol. 1997; 35: 39-66.

SteilingW, Brachter M, Coutellemont P, de Silva O. The HET-CAM, a useful In vitro assay for assessing the eye irritation properties of cosmetic formulations and ingredients. Toxicol In Vitro. 1999; 13: 375-384.

Takahashi Y, Hayashi T, Watanabe S, Hayashi K, Koike M, Aisawa N, et al. Inter-laboratory study of short time exposure (STE) test for predicting eye irritation potential of chemicals and correspondence to globally harmonized system (GHS) classification. J Toxicol Sci. 2009; 34 (6): 611-626.

Vinardell MP, Mitjans M. The chorioallantoic membrane test as a model to predict the potential human eye irritation induced by commonly used laboratory solvents. Toxicol in Vitro. 2006; 20 (6): 1066-1070.

Vinardell MP, Mitjans M. Alternative methods for eye and skin irritation tests: An overview. J Pharm Sci. 2008; 97 (1): 46-59.

Wax PM. Elixirs, diluents, and the passage of the 1938 Federal Food, Drug and Cosmetic Act. Ann Intern Med. 1995; 122 (6): 456-61.

Wilhelmus KR. Therapeutic reviews: the Draize Eye Test. Surv Ophthalmol. 2001; 45 (6): 493-515.

Received: January 13, 2011; Revised: July 15, 2011; Accepted: February 16, 2012. 